\title{
ENTREVISTA: Dr. Raul Marino Júnior ${ }^{1}$
}

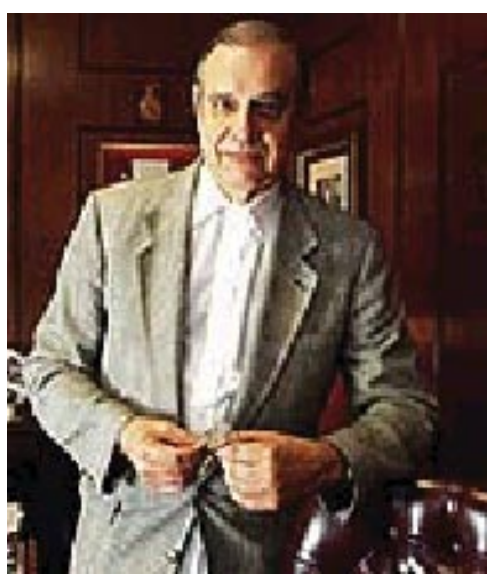

Dr. Raul Marino Júnior, formado pela Faculdade de Medicina da USP no ano de 1961, deixou o cargo de professor titular da Neurocirurgia no início desse ano. Ao longo de uma carreira profissional brilhante, Dr. Raul Marino soube conciliar o conhecimento filosófico, religioso e médico para edificar uma trajetória que inclui não apenas a inauguração da Neurologia funcional no país, mas também a autoria de livros que tratam do cérebro, das emoções e religião como poucos já trataram. Em seu último livro, A Religião do Cérebro, dá um depoimento sobre as experiências religiosas e místicas e sua relação com a fisiologia cerebral.

\section{R.M.: Ao longo de sua carreira médica senhor acumulou um currículo muito rico com cursos, congressos, doutorado, MIT (Massachusetts Institute of Technology), livre docência, literatura... $O$ que 0 senhor tem a dizer e o que considera mais marcante na sua carreira?}

Acho que a Fundação da Neurocirurgia Funcional, pela qual fui um dos responsáveis no mundo. Hoje existe a Sociedade Mundial de Neurocirurgia Funcional e Esteriotaxia, que é paralela à Sociedade Mundial de Neurocirurgia. Essa separação ocorreu porque os nossos objetivos são diferentes, nós não visamos retirar lesões, tumores, clipar aneurismas; nós trabalhamos em um cérebro intacto. Você lesa um núcleo talâmico em um paciente com Parkinson para curar um tremor, lesa o lobo temporal em outro para curar uma epilepsia. Em um cérebro normal, você trabalha com a função. Na dor, por exemplo, não há nada errado no cérebro do indivíduo, mas você pode tratar com eletrodos; pode tratar uma epilepsia também com eletrodos no cerebelo, colocar um marca-passo cerebelar. Nós tratamos também distúrbios endócrinos, como Doença de Cushing, acromegalia, tumores neurofuncionantes da hipófise, além de outras doenças como Parkinson, um tipo de cirurgia bem especial.

R.M.: O senhor teve muitas oportunidades fora do país. Como essas experiências surgiram durante a sua carreira e como elas influenciaramna?

Eu sempre tive planos de não ficar no Brasil. Aprendi muito durante meus anos de residência aqui. No meu tempo eram quatro anos e eu era o único residente

\footnotetext{
1. Prof. Emérito do Departamento de Neurocirurgia. Doutor em Medicina pela Faculdade de Medicina da Universidade de São Paulo.

Endereço para correspondência: revistademedicina@dc.fm.usp.br
} 
na Neurocirurgia. Imaginem o volume de trabalho que eu tinha. Hoje em dia são cinco residentes por ano num total de vinte e cinco no serviço como um todo. Depois que terminei a residência, prestei um concurso e ganhei uma bolsa na União Cultural Brasil-Estados Unidos. Com isso fui para Boston estudar na Harvard Medical School. Estudei também, neuroanatomia nos laboratórios de Anatomia do Massachusetts Institute of Technology (MIT); e depois fui para a McGill University (Montreal) onde aprendi muito sobre cirurgias da hipófise e epilepsia. Trabalhei ainda no estudo da fisiologia do Sistema Límbico durante um ano. Quando retornei para o Brasil escrevi um livro, Fisiologia das Emoções, a respeito desse Sistema quase desconhecido no país. Foi meu primeiro livro. Além desse, lancei um sobre epilepsia, um sobre a história do Japonês, outro sobre a vida de Sr. Willian Osler e agora esse: A Religião do Cérebro. Nele alio os conhecimentos médicos aos obtidos nos meus estudos de Teologia e Filosofia. Eu fiz Teologia na Pontifícia Faculdade Assunção de Teologia. Na época, meus residentes pensavam que eu estava ficando louco. O curso de Filosofia eu fiz quando ainda era estudante de Medicina.

\section{R.M.: E como o senhor conseguia conciliar as duas faculdades?}

Dava tempo de fazer tudo. Eu saia da Anatomia às seis horas da tarde e ia para a Rua Maria Antonia estudar Filosofia. Quando eu entrei na Medicina, eu queria fazer Psiquiatria. Foi assim até meu quinto ano e naquela época eu era o único estagiário da Psiquiatria. Mais tarde durante o curso, quando vi que tinha mão boa para a cirurgia eu desisti e acabei fazendo Neurocirurgia. Na época da faculdade eu tive um laboratório na Histologia, no qual estudei o Sistema Nervoso. Eu operava ratos, estudava a glândula pineal. Fiz isso por cinco anos, e foi muito proveitoso. Depois fiz um estágio na Patologia, fui monitor da Neuroanatomia. Nessa época eu achei que devia aprender línguas. Fiz cursos na União Cultural e estudei literatura americana, fiz Aliança Francesa, além de ter aprendido Espanhol, Italiano, Alemão e Japonês. O Inglês foi essencial não só para as publicações, mas também para a minha experiência fora do país. Quando eu cheguei aos Estados Unidos eu falava como um americano, ninguém sabia de onde eu era. Além disso, o conhecimento das outras línguas foi fundamental para a minha carreira como um todo.

\footnotetext{
R.M.: Quando o senhor foi preceptor da residência de Neurocirurgia, criou a formatura do final do curso. Por que o senhor acha isso importante?
}

Eu acho muito importante os residentes terem uma festa para família. Porque é o segundo curso de medicina que eles acabam e a neurocirurgia dura "apenas" cinco anos. Eles acabam a faculdade, entram num curso que demanda muita dedicação, têm que concorrer com pessoas de fora, de outras faculdades de medicina, e mesmo com outros da FMUSP. Às vezes chegam pessoas com currículos incríveis e nós temos que aceitar. Quando eu cheguei lá, em 1990, eu estranhei porque os residentes saiam e não davam nem até logo para nós, e eu era o professor da cadeira na época. Então, criei uma festa de formatura anual em que eram convidadas as famílias dos residentes. Começou no Centro de Convenções Rebouças, depois foi evoluindo, crescendo, até que consequi o patrocínio da Jonnson's. Hoje em dia, as últimas todas foram no Baiúca que é um lugar maravilhoso. As famílias saem todas chorando, tem um discurso no qual eu entrego os certificados nas mãos de cada um, tiramos fotografias, tudo é filmado. São festas com música clássica, buffet maravilhoso, e as famílias saem todas elevadas. Agora os residentes não saem mais sem dar até logo. Tem a despedida, tem aquele discurso lindo, nele dou um monte de conselhos a eles, falo da Bíblia, da neurologia, do que os espera lá fora. Virou uma festa obrigatória, eu não sei por que as outras disciplinas não fazem isso. O dia mais feliz da minha vida é no mês de dezembro no dia da despedida dos R5. E eles gostam tanto que no ano passado, 2006, eu já estava retirado e convidaramme para fazer o discurso. Fiquei emocionado.

\section{R.M.: O que mais surgiu durante a gestão do senhor como preceptor da neurocirurgia?}

Nós criamos também um congresso só para os residentes, fundei a sociedade dos ex-residentes do HC. E eu acho que todos os meus ex-residentes formam uma família no Brasil inteiro. No congresso do ano passado nós tivemos uma videoconferência no Rebouças com amigos meus do Canadá, Estados Unidos. Esse ano ela aconteceu novamente, mas infelizmente sem a minha presença. O que eu deixei na residência foi um ambiente quase familiar. Agora todos têm a sociedade de ex-residentes da neurocirurgia, criamos a Liga de Neurocirurgia, a Liga de Dor, recriamos a Liga de Epilepsia, que é a mais antiga de todas e estava morta quando eu cheguei ao cargo, e criamos a Liga da Cefaléia.

\section{R.M.: E a criação destas ligas surtiu efeito?}

Eu as recomendo a todos os alunos, nem que façam pelo menos o curso, porque isso dá título. Alguns 
alunos meus do quarto ano ganharam prêmio de melhor trabalho e tiveram muitos outros que trabalharam comigo no LIM-45, que eu coordenava e passei para frente. Eu creio que nós conseguimos criar a melhor residência de neurocirurgia do Brasil, pelo menos é o que dizem! É a única que tem R5, as outras vão só até o R4. Eu acho que é no quinto ano que eles operam mais, eles ficam residentes-chefe do quarto pro quinto ano. Acho que fiquei todos esses anos agüentando todo esse trabalho no $\mathrm{HC}$, às vezes, por causa dos residentes, não por causa dos assistentes ou de mim mesmo. Eu achei que minha missão era formá-los, e nós formamos às vezes quatro, às vezes cinco, todo ano. E nem todos da FMUSP, tenho residentes do Japão, do Ceará, da Paraíba, Espírito Santo, Amazonas, temos da escola Paulista, Londrina, Rio de Janeiro! Praticamente $90 \%$ ficam aqui no HC.

\section{R.M.: Em 1977 o senhor participou da fundação da Divisão de Neurocirurgia funcional e o Centro de Estudos em Fisiologia Humana do HC. Qual a contribuição desse centro para a neurologia atual como um todo?}

Quando eu voltei dos Estados Unidos, onde fiquei muitos anos estudando anatomia do Sistema Límbico, epilepsia e neuroendocrinologia; nós fundamos a Sociedade Brasileira de Neuroendocrinologia, que hoje é uma entidade autônoma e ligada ao grupo da Endocrinologia. Depois disso eu escrevi um livro sobre Neurocirurgia funcional, que foi o primeiro na literatura mundial. Nessa época, entrei no serviço de Neurologia e imediatamente me tornei preceptor dos residentes, um cargo que até então não existia. Porém, por um desentendimento com a cúpula da Neurologia na época, acabei pedindo demissão e fui para a Psiquiatria. Lá, eu fundei o Centro de Neurocirurgia Funcional, onde se realizava um tipo de cirurgia que não era conhecido no país. Aqui se retiravam tumores, clipavam aneurismas, mas ninguém operava epilepsia, neuroendocrinologia, tumores da hipófise, dor. Havia 51 leitos e só eu operava. Bom, todos os dias havia cirurgias de hipófise, dor, epilepsia; foi aí que escrevi minha tese de doutorado em Psicocirurgia. Era estranho porque os psiquiatras não estavam mais interessados em receitar tantos remédios, pois, na prática, viu-se que o negócio (cirurgia) curava muita gente. Imediatamente o serviço ficou conhecido e muitas pessoas de fora vinham conhecê-lo. Vários profissionais formaram-se nesse centro, em uma especialidade nova que só existia no Hospital das Clínicas.

\section{R.M.: E este Centro funciona até os dias atuais?}

Funciona até hoje, mas o reconhecimento que nos tínhamos da Câmara Federal como um serviço de utilidade pública foi perdido. Nós não pagávamos impostos, ganhávamos doações. Havia um grupo de contribuidores que nos sustentava com doações. Ali muitas pessoas se formaram, incluindo neurologistas, psiquiatras especializados em cérebro, neurofisiologistas, eletroencefalografistas. A neuropsicologia começou lá e chegou a formar mais de dez profissionais que hoje estão espalhados pelo Brasil inteiro. Eu fiquei operando no Centro por muitos anos, até a época em que me tornei Professor Titular da Neurologia, lugar onde fiquei dando aulas por 15 anos e acabei por fundar outra divisão, a da Clínica Neurocirúrgica. 